\title{
Postmortem Redistribution of Lidocaine after Epidural Anesthesia Accidental Death
}

\author{
Zhiwen Wei ${ }^{1}$, Jie $\mathrm{Yu}^{2}$, Chao Zhang ${ }^{1}$, Juan $\mathrm{Jia}^{1}$, Jie Cao ${ }^{1}$, Yujin Wang ${ }^{1}$, Cairong Gao ${ }^{1}$, Yingyuan Wang ${ }^{1}$ and Keming Yun ${ }^{{ }^{*}}$ \\ ${ }^{1}$ School of Forensic Medicine, Shanxi Medical University, Taiyuan, People's Republic of China \\ ${ }^{2}$ The Public Security Bureau of Jiancaoping, Taiyuan City, Taiyuan, People's Republic of China
}

"Corresponding author: Keming Yun, School of Forensic Medicine, Shanxi Medical University, 56 Xinjian South Road, Taiyuan, 030001 , People's Republic of China, Tel: +86-351-4135537; E-mail: yunkeming5142@163.com

Received date: November 01, 2017; Accepted date: January 05, 2017; Published date: January 09, 2017

Copyright: $\odot 2017$ Zhiwen W, et al. This is an open-access article distributed under the terms of the Creative Commons Attribution License, which permits unrestricted use, distribution, and reproduction in any medium, provided the original author and source are credited.

\begin{abstract}
Epidural anesthesia is often used form in Chinese primary hospitals and lidocaine is the most favorite anesthetic. Fatalities due to epidural anesthesia accident and lidocaine overdose are often happened, but there still have not obvious evidence to indicate the real reason of death according to the concentration of lidocaine in postmortem blood because the postmortem redistribution (PMR). An animal models using dogs has been developed, whereby the dogs received an intravenous, subarachnoid, and epidural injection of lidocaine ( $75 \mathrm{mg} / \mathrm{kg}$ body weight). The dogs were placed at room temperature after sacrifice. The cardiac blood, inferior vena cava blood, liver and cerebrum samples were collected at $0 \mathrm{~h}, 1 \mathrm{~h}, 4 \mathrm{~h}, 8 \mathrm{~h}, 24 \mathrm{~h}, 48 \mathrm{~h}$ and $72 \mathrm{~h}$ postmortem with the same animal's corpse. The lidocaine is easier diffusion from canalisvertebralis to cardiac blood in subarachnoid administration. The level commonly has a great change from $48 \mathrm{~h}$ after death in cardiac blood, from $35.7 \mathrm{mg} / \mathrm{L}$ to $1421.9 \mathrm{mg} / \mathrm{L}$, and then decreasing $50 \%$ at $72 \mathrm{~h}$. The inferior vena cava blood concentration was stabilized in postmortem time. The cerebrum concentration of subarachnoid administration decreased by $50 \%$ and was observed at $72 \mathrm{~h}$ after death. The changes were observed in cardiac blood in intravenous and epidural administration groups, but no changes were observed in cerebrum. Lidocaine concentrations did not change significantly in the liver in any of the three groups. This study can assist toxicologists to determine which specimens should be the most appropriately during the interpretation of lidocaine concentrations in epidural accidents.
\end{abstract}

Keywords: Lidocaine; Postmortem redistribution; Epidural anesthesia; Accident

\section{Introduction}

Epidural anesthesia is the most commonly used forms of central neuraxial blockade. It can be used as an analgesic adjuvant to general anesthesia, the sole anesthetic for procedures involving the lower limbs, pelvis, perineum, lower abdomen or thorax and it is the most popular method of pain relief during surgery, obstetrics and pain control. Epidurals block nerve impulses from the lower spinal segments, it results in decreased sensation in the lower half of the body. Epidural medications often use local anesthesia which blocks pain in a particular region of the body, including lidocaine, bupivacaine, or procaine. As the first aminoamide-type local anesthetic, it was synthesized in 1943 as xylocaine. Lidocaine is a drug commonly used as a local anesthetic and as an antiarrhythmic and it also used as an epidural anesthesia or combined spinal-epidural (CSE). Meanwhile, Epidural anesthesia remains a fundamental part of China primary hospital of anesthesia, because of its success, predictability, and low complication rate.

At recent years, fatalities due to epidural anesthesia accident are often happened [1-4], and many cases of poisoning resulting from its overdose have been reported [5-8]. As far as forensic toxicological identification, analytical methods for lidocaine are well developed and documented [9-11]. However, there is no obvious evidence indicated the cause of death in anesthesia, difficult to distinguish the cause of death between accident and natural. Single injection and catheter techniques are the two basic methods during epidural anesthesia. The most common cause of epidural anesthesia faults occurred during placement. There have many reasons caused accident, anesthetist's malpractice, complicated canalisvertebralis structure etc. General risks include dual puncture by the spinal needle or incorrect catheter placement during epidural anesthesia, the local anesthetic may be injected into the vein for canalisvertebralis rich vasculature, the catheter may be misplaced to the subarachnoid space, anesthetist did not found fault or the catheter was placed correctly into the epidural space but the anesthetic dose exceeded the maximum permissible doses. The detection of toxicants in postmortem cases is more difficult than in clinically derived specimens. Because many reasons influenced the concentration of toxicants in blood, which included postmortem redistribution, the stability of toxicants in different biological samples etc. Therefore, interpreting the test results remain a challenge for forensic toxicologists due to the lack of postmortem redistribution data for the lidocaine before autopsy. The aim of this study was to investigate the postmortem redistribution of lidocaine in epidural anesthesia accident, to compare the changes in concentrations in these three different path poisoning death, intravenous, subarachnoid space and epidural injection, along with the samples collected times during the ambient temperature.

\section{Materials and Methods}

\section{Animals}

Animals were Chinese male dogs weighing $18 \mathrm{~kg}$ to $21 \mathrm{~kg}$ and provided by the laboratory animal center of Shanxi Medical University. 
Page 2 of 5

Nine dogs were used during the experiments and divided into three groups and three dogs for each group. All experiments were performed in accordance with the Regulations of Shanxi province laboratory animal management governing animal studies. The dogs were administrated $2 \%$ lidocaine hydrochloride solution. A single dose of 75 mg of lidocaine per kilogram body weight was administrated to each dog. Group 1 was given by intravenous injection. Group 2 was given by subarachnoid space and Group 3 was given by epidural. Before the experiments, dogs were emptied stomach $12 \mathrm{~h}$, but water was allowed ad labium.

\section{Chemicals}

Lidocaine was obtained from the Institute of Forensic Science Ministry of Public Security PRC and was prepared $1 \mathrm{mg} / \mathrm{ml}$ in ethanol. Lidocaine hydrochloride injection was purchased from the Hospital of Shanxi Medical University (H31021071, China). All solvents used were analytic grade.

\section{Experiments}

Dogs were administered lidocaine injections at a constant rate during five minutes by intravenous, subarachnoid, or epidural injections, respectively. Electrocardiograms, Heart rate, blood pressure and respiration were measured at experiments from preadministration to death with a biological function system. After sacrifice, dogs were placed in a left recumbent position at ambient temperature $\left(19^{\circ} \mathrm{C}\right.$ to $\left.23^{\circ} \mathrm{C}\right)$. The cardiac blood, inferior vena cava blood, liver, and cerebrum samples were collected at $0 \mathrm{~h}, 1 \mathrm{~h}, 4 \mathrm{~h}, 8 \mathrm{~h}$, $24 \mathrm{~h}, 48 \mathrm{~h}$, and $72 \mathrm{~h}$ postmortem (three dogs for each experimental group). The inferior vena cava blood was limited to $2 \mathrm{~mL}$ in order to prevent drawing blood from the upper cardiac blood. After samples had been collected at each postmortem interval (PMI), the dogs were completely sutured. All fluid samples were stored at $4^{\circ} \mathrm{C}$, and solid samples were kept at $-20^{\circ} \mathrm{C}$ until analysis.

\section{Analytical method}

The matrices were extracted using liquid-liquid extraction and the concentration of lidocaine was determined using gas chromatographymass spectrometry (Thermo fisher, TRACE DSQ). The GCMS was operated with a transfer line temperature of $250^{\circ} \mathrm{C}$ and a source temperature of $250^{\circ} \mathrm{C}$. The GC was equipped with a $30-\mathrm{m}$ TRACE TR-5MS capillary column with helium as the carrier gas set at a flow rate of $1.0 \mathrm{ml} / \mathrm{min} .1 \mu \mathrm{L}$ of the extractive was injected into the GCMS. The GC was equipped with a splitless injection port operated at $280^{\circ} \mathrm{C}$ in the split mode with a purge time of two minutes. The oven temperature profile was established as follows: $150^{\circ} \mathrm{C}$ hold time $1 \mathrm{~min}$ to $280^{\circ} \mathrm{C}$ at $10^{\circ} \mathrm{C} / \mathrm{min}$ and a final hold time of $2 \mathrm{~min}$, resulting in a total run time of $16 \mathrm{~min}$. The MS was operated in the selected ionmonitoring mode and the following ions were monitored: quantitating ion 86 and qualifier ions 58 and 86.

\section{Results}

\section{The variation of vital signs}

The changes of heart rate, blood pressure and respiration from antemortem to death in intravenous, subarachnoid, and epidural administration are given in Tables 1-3 respectively.

\begin{tabular}{|l|l|l|l|}
\hline Time & Electrocardiogram & Respiratory & Blood pressure \\
\hline Before the injection & Regular & Regular & Regular \\
\hline In injection process & Accelerated & Accelerated & Elevated \\
\hline 4 min after injection & Slow & Long, fast & The highest \\
\hline 6 min after injection & Bradyarrhythmia, irregular & Cheyne-Stokes breath & Disappearance \\
\hline 8 min after injection & Atrial flutter, Ventricular Fibrillationdisappearance & Slower and disappearance & Disappearance \\
\hline Mean disappear time & $8(6-10)$ min & $7.2(4-9)$ min & $6.5(5-8)$ min \\
\hline
\end{tabular}

Table 1: Variation of vital signs in intravenous administration dogs.

\begin{tabular}{|c|c|c|c|}
\hline Time & Electrocardiogram & Respiratory & Blood pressure \\
\hline Before the injection & Regular & Regular & Regular \\
\hline 2 min after injection & Slow & Accelerate & Elevate \\
\hline Injection finished & Accelerate, Ventricular Fibrillation & Long, fast & Lower \\
\hline 2 min after injection finished & Bradyarrhythmia, irregular & Cheyne-Stokes breath & Lower \\
\hline 7 47 min after injection finished & $\begin{array}{lrr}\text { Atrial } & \text { flutter, } & \text { Ventricular } \\
\text { Fibrillationdisappearance } & \end{array}$ & Slower and disappearance & Disappearance \\
\hline Mean disappear time & 23.8(7 42 min) & $18.6(10 \sim 47) \min$ & $16.4(7 \sim 35) \min$ \\
\hline
\end{tabular}

Table 2: Variation of vital signs in subarachnoid administration dogs. 
Citation: Wei Z, Yu J, Zhang C, Jia J, Cao J, et al. (2017) Postmortem Redistribution of Lidocaine after Epidural Anesthesia Accidental Death. J

Page 3 of 5

\begin{tabular}{|l|l|l|l|}
\hline Time & Electrocardiogram & Respiratory & Blood pressure \\
\hline Before the injection & Regular & Regular & Regular \\
\hline 2 min after injection & Accelerate & Accelerate & Elevate \\
\hline Injection finished & Accelerate & Long, fast & Lower \\
\hline 18 min after injection finished & Bradyarrhythmia, irregular & Cheyne-Stokes breath & Lower \\
\hline $23 \sim 30$ min after injection finished & Atrial flutter, Ventricular Fibrillationdisappearance & Slower and disappearance & Disappearance \\
\hline Mean disappear time & 23.6 min & 21.4 min & 23.6 min \\
\hline
\end{tabular}

Table 3: Variation of vital signs in epidural administration dogs.

The respiration and blood pressure mean disappear time by intravenous injection was also the fastest disappeared time of the three groups. They were $18.6 \mathrm{~min}$ and $16.4 \mathrm{~min}$ by subarachnoid administration, $21.4 \mathrm{~min}$ and $23.6 \mathrm{~min}$ by epidural administration. The heart rate disappeared time was $8 \mathrm{~min}$ after intravenous injection. It was the fastest of the three groups compared to $23.8 \mathrm{~min}$ by subarachnoid injection and $23.6 \mathrm{~min}$ by epidural administration.

\section{The changes of lidocaine concentrations in postmortem blood samples}

Postmortem blood lidocaine concentration by intravenous injections ranged from $34.9 \mathrm{mg} / \mathrm{L}$ to $29.3 \mathrm{mg} / \mathrm{L}$ in the inferior vena cava blood, and from $123.5 \mathrm{mg} / \mathrm{L}$ to $32.1 \mathrm{mg} / \mathrm{L}$ in cardiac blood. Results are shown in Figure 1. The inferior vena cava blood increased 1 $\mathrm{h}$ postmortem after death and then decreased slightly. In cardiac blood, drug concentrations decreased fourfold at $72 \mathrm{~h}$. Figure 2 shows the postmortem changes in blood observed for lidocaine concentration by subarachnoid administration.

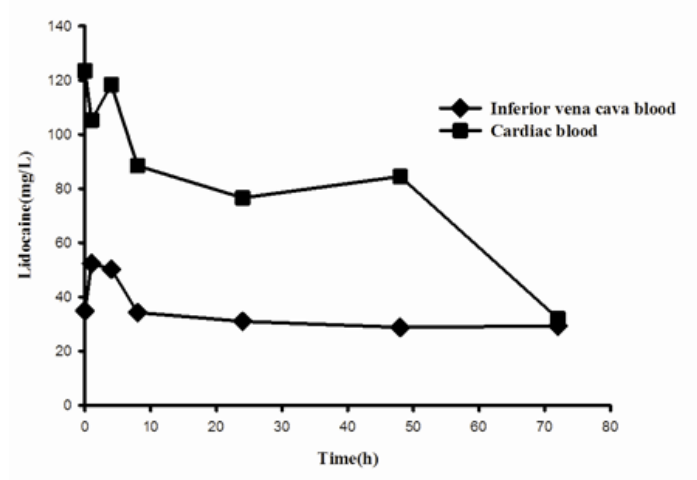

Figure 1: Effect of Postmortem interval time conditions in blood at intravenous administration.

The lidocaine concentration did not change significantly in the inferior vena cava blood. On the other hand, the cardiac blood concentration increased significantly at $48 \mathrm{~h}$ postmortem from 35.7 $\mathrm{mg} / \mathrm{L}$ to $1421.9 \mathrm{mg} / \mathrm{L}$, it was about fortyfold, then decreased of $50 \%$ was observed between $48 \mathrm{~h}$ to $72 \mathrm{~h}$ postmortem. Figure 3 presents the postmortem changes in blood observed for lidocaine concentration by epidural administration. The inferior vena cava blood and cardiac blood concentrations were increased in the first $8 \mathrm{~h}$, decreased from 8 $\mathrm{h}$ to $24 \mathrm{~h}$ after death and then increased from $24 \mathrm{~h}$ to $72 \mathrm{~h}$ after death. The change of lidocaine concentration in inferior vena cava blood and cardiac blood was consistent after death.

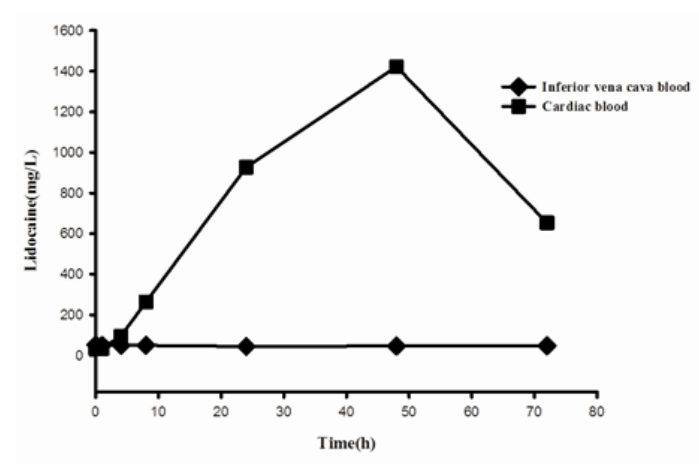

Figure 2: Effect of postmortem interval time conditions in blood at subarachnoid administration.

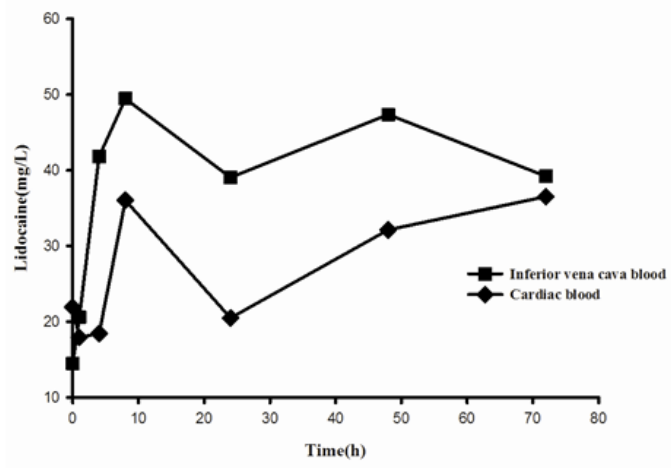

Figure 3: Effect of postmortem interval time conditions in blood at epidural administration. 


\section{Times varying of lidocaine concentration in different tissues}

Figures 4-6 present the postmortem changes observed for lidocaine concentration by different administration pathways. For three administration pathways (intravenous, subarachnoid and epidural), the lidocaine concentrations did not change significantly in the liver. The cerebrum concentration by subarachnoid (Figure 5) decreased by $50 \%$ and was observed at $72 \mathrm{~h}$ after death. For the intravenous and epidural administration, the cerebrum concentrations did not change.

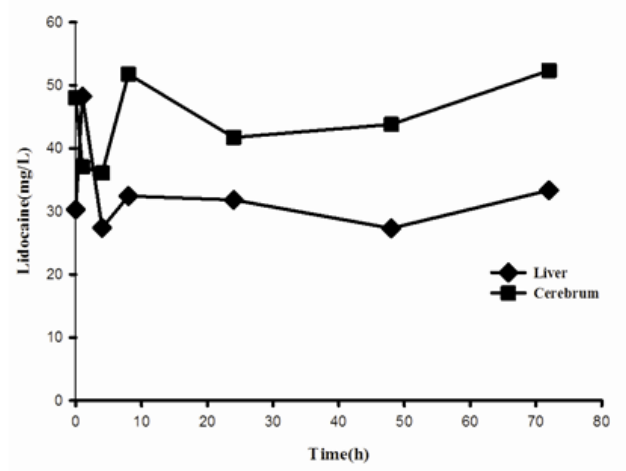

Figure 4: Effect of Postmortem interval time conditions in tissues at intravenous administration.

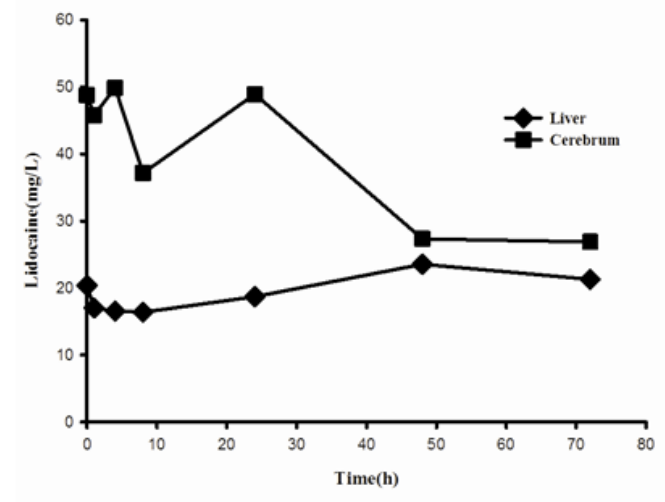

Figure 5: Effect of postmortem interval time conditions in tissues at subarachnoid administration.

\section{Discussion}

Postmortem redistribution processes potentially affect the concentration of all toxicants in postmortem cases as a result of diffusion of toxicant from higher to lower concentrations following disruption of cellular membranes [12-18]. In particular, the concentration of heart blood is influenced by this process. It is particularly significant for toxicants with high lipid solubility, high apparent volume of distribution (Vd) greater than $3 \mathrm{~L} / \mathrm{kg}$, or high tissue concentrations relative to blood taken from the heart. It had be proved by many examples include the tricyclic antidepressants [17-22], dioxin [19-24] and the amphetamines [25]. To the best of our knowledge, there is a few study investigated the postmortem redistribution of lidocaine. The volume distribution of lidocaine is 1.1 $\mathrm{L} / \mathrm{kg}$ to $2.1 \mathrm{~L} / \mathrm{kg}$, and the structure includes hydrophilic and lipophilic groups. Along with $\mathrm{pH}$, it expresses different functions. Some studies have investigated the postmortem diffusion of basic drugs into cardiac blood from surrounding tissues and tracheal and lidocaine could diffusion into the blood after intubation by cardiopulmonary resuscitation $[25,26]$.

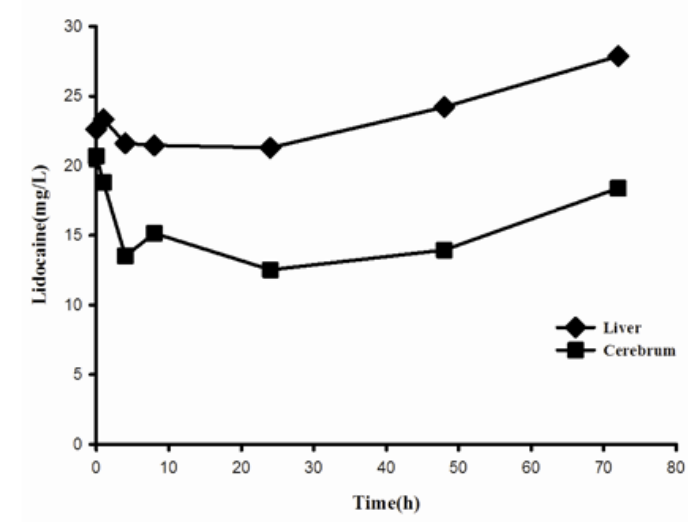

Figure 6: Effect of postmortem interval time conditions in blood at epidural administration.

The animal models by intravenous, subarachnoid and epidural administration lidocaine have been developed. In three groups of different administration pathways, the concentration of lidocaine in postmortem cardiac blood was influenced by PMR phenomenon. The cardiac blood concentration in subarachnoid space was more significant changed along with postmortem interval. In particular, there was a significant change in autopsy and $48 \mathrm{~h}$ after death postmortem cardiac blood ( $35.7 \mathrm{mg} / \mathrm{L}$ versus $1421.9 \mathrm{mg} / \mathrm{L})$, and then decreased $50 \%$ at $72 \mathrm{~h}$. A slightly larger change in intravenous and epidural postmortem cardiac blood from autopsy to $72 \mathrm{~h}$ after death (123.5 mg/L versus $32.1 \mathrm{mg} / \mathrm{L}, 21.9 \mathrm{mg} / \mathrm{L}$ versus $36.5 \mathrm{mg} / \mathrm{L}$, respectively), it was obvious different to observed in subarachnoid administration. The inferior vena cava blood concentration was not changed significantly in each group. For overdose lidocaine, there is a reservoir of unabsorbed lidocaine in canalisvertebralis. The subarachnoid administration group was easily diffused from canalisvertebralis to cardiac blood. The epidural space is the airtight area of space that surrounds the dural sac and is bounded by the posterior longitudinal ligament anteriorly, the ligamentaflava, and the periosteum of the laminae posteriorly. The lidocaine was closed in the space could hardly diffusion from the epidural space.

Human cases often relied on experimental animal studies, such as rats [27-33] to study postmortem toxicant redistribution, these animal models were dissected corpses in postmortem different interval time. About three to six animals were autopsied at each postmortem time. The greater individual difference would cause unstable experimental data, and it will influence the study of postmortem redistribution. This study established the whole animal models to study the postmortem lidocaine redistribution. The sacrificial animals were placed along with unified position (left lateral position). The samples were collected with the same animal's organ at different postmortem interval time. The situation of sample collected and detected is similar with actual cases. It can effective avoid the influence of individual difference. 


\section{Conclusion}

The present study reported that lidocaine concentration changes in samples depending on the way of lidocaine intake and postmortem interval times. The subarachnoid administration is easier diffusion from canalisvertebralis to cardiac blood. The lidocaine concentration commonly has a great change from $48 \mathrm{~h}$ after death in cardiac blood. The inferior vena cava blood concentration was stabilized in postmortem time. Finally, the whole animal models are the better way to study postmortem redistribution. To interpret the results of toxicological, if specimens are available, analysis of both blood cerebrum and liver is recommended, especially the cardiac and inferior vena cava blood. Meanwhile, this study can assist toxicologists to determine which specimens should be the most appropriately in epidural accidents.

\section{Acknowledgement}

This work was supported by the National Key Technology R \& D Program of China (No. 2007BAK26B05 and No. 2012BAK02B02), National Natural Science Foundation of China (N0.81172906), and Natural Science Foundation for Young Scientists of Shanxi Province, China (No. 2010021038-1). Additionally, the authors wish to thank Dr. Pfeiffer, Mary for her valuable assistance with manuscript preparation.

\section{References}

1. Van Zundert AA, Scott DB (1989) A fatal accident after epidural anesthesia for cesarean section. Acta anaesthesiologica Belgica 40: 195-199.

2. Harti A, Benslama A, M'Jahed H, Zinoun N, Louardi H, et al. (1992) Cardiac arrest and epidural anesthesia. Agressology: international journal of physio-biology and pharmacology applied to the effects of aggression 33: 183-184.

3. Le Borgne S, Robillart A, Zeisser M, Mangin M, Dupeyron JP (1991) The association of continuous peridural anesthesia with general anesthesia. Apropos of 2 accidents. Cahiers D'anesthesiologie 39: 171-174.

4. Palkar NV, Boudreaux RC, Mankad AV (1992) Accidental total spinal block: a complication of an epidural test dose. Can J Anaesth 39: 1058-1060.

5. Hasegawa M, Fujihara J, Takatsuka H, Chung HC, Takeshita H (2008) A case of sudden death after gingival injection of a therapeutic dose of lidocaine: distribution of lidocaine in whole blood and various tissues. Forensic Toxicol 26: 41-44.

6. de Barros Duarte L, Dantas Moises EC, Cavalli RC, Lanchote VL, Duarte $\mathrm{G}$, et al. (2011) Distribution of bupivacaine enantiomers and lidocaine and its metabolite in the placental intervillous space and in the different maternal and fetal compartments in term pregnant women. J Clin Pharmacol 51: 212-217.

7. Kudo K, Nishida N, Kiyoshima A, Ikeda N (2004) A fatal case of poisoning by lidocaine overdosage-analysis of lidocaine in formalin-fixed tissues a case report. Med Sci Law 44: 266-271.

8. Poklis A, Mackell M, Tucker E (1984) Tissue distribution of lidocaine after fatal accidental injection. J Forensic Sci 29: 1229-1236.

9. Raikos N, Theodoridis G, Alexiadou E, Gika H, Argiriadou H, et al (2009) Analysis of anaesthetics and analgesics in human urine by headspace SPME and GC. J Sep Sci 32: 1018-1026.

10. Halbert MK, Baldwin RP (1984) Determination of lidocaine and active metabolites in blood serum by liquid chromatography with electrochemical detection. J Chromatogr 306: 269-277.
11. Chen L, Liao L, Zuo Z, Yan Y, Yang L, et al. (2007) Simultaneous determination of nikethamide and lidocaine in human blood and cerebrospinal fluid by high performance liquid chromatography. J Pharm Biomed Anal 43: 1757-1762.

12. Drummer OH, Gerostamoulos J (2002) Postmortem drug analysis: analytical and toxicological aspects. Therapeutic drug monitoring 24 199-209.

13. Drummer OH (2004) Postmortem toxicology of drugs of abuse. Forensic Sci Int 142: 101-113.

14. Drummer OH (2007) Post-mortem toxicology. Forensic Sci Int 165: 199-203.

15. Drummer OH (2010) Forensic toxicology. Exs 100: 579-603.

16. Kennedy MC (2010) Post-mortem drug concentrations. Intern Med 40: 183-187.

17. Madea B, Musshoff F (2004) Postmortem toxicology. Forensic Sci Int 142 71-73.

18. Wyman JF (2012) Principles and procedures in forensic toxicology. Clin lab med 32: 493-507.

19. Koren G, MacLeod SM (1985) Postmortem redistribution of digoxin in rats. J Forensic Sci 30: 92-96.

20. Bentur Y, Tsipiniuk A, Taitelman U (1999) Postmortem digoxin-like immunoreactive substances (DLIS) in patients not treated with digoxin. Hum Exp Toxicol 18: 67-70.

21. Deveaux M, Revuelta E, Mornay E, Hedouin V, Gosset D (1997) Immunoassay of digoxin in hair. Forensic Sci Int 84: 219-223.

22. McKercher HG, Mikhael NZ, De Gouffe M, Lukaszewski T, Peel HW (1986) Digoxin concentrations in postmortem human tissues. Res Commun Chem Pathol Pharmacol 52: 141-144.

23. Shepherd MF, Lake KD, Kamps MA (1992) Postmortem changes and pharmacokinetics: review of the literature and case report. The Annals of pharmacotherapy 26: 510-514.

24. Yarema MC, Becker CE (2005) Key concepts in postmortem drug redistribution. Clin Toxicol (Phila) 43: 235-241.

25. Moriya F, Hashimoto Y (1999) Redistribution of basic drugs into cardiac blood from surrounding tissues during early-stages postmortem. J Forensic Sci 44: 10-16.

26. Moriya F, Hashimoto Y (1997) Postmortem diffusion of tracheal lidocaine into heart blood following intubation for cardiopulmonary resuscitation. J Forensic Sci 42: 296-299.

27. Castaing N, Titier K, Canal-Raffin M, Moore N, Molimard M (2006) Postmortem redistribution of two antipsychotic drugs, haloperidol and thioridazine, in the rat. J Anal Toxicol 30: 419-425.

28. Hilberg T, Morland J, Bjorneboe A (1994) Postmortem release of amitriptyline from the lungs; a mechanism of postmortem drug redistribution. Forensic Sci Int 64: 47-55

29. Hilberg T, Ripel A, Slordal L, Bjorneboe A, Morland J (1999) The extent of postmortem drug redistribution in a rat model. J Forensic Sci 44: 956-962.

30. Hilberg T, Rogde S, Morland J (1999) Postmortem drug redistributionhuman cases related to results in experimental animals. J Forensic Sci 44 3-9.

31. Kugelberg FC, Druid H, Carlsson B, Ahlner J, Bengtsson F (2004) Postmortem redistribution of the enantiomers of citalopram and its metabolites: an experimental study in rats. J Anal Toxicol 28: 631-637.

32. Kugelberg FC, Kingback M, Carlsson B, Druid H (2005) Early-phase postmortem redistribution of the enantiomers of citalopram and its demethylated metabolites in rats. J Anal Toxicol 29: 223-228.

33. Rogde S, Hilberg T, Teige B (1999) Fatal combined intoxication with new antidepressants. Human cases and an experimental study of postmortem moclobemide redistribution. Forensic Sci Int 100: 109-116. 